\title{
A Clínica Psicanalítica na Saúde Pública: Desafios e Possibilidades
}

The Psychoanalytic Clinic on Public Health: Challeges and Opportunities

La Clínica Psicoanalítica en La Salud Pública: Desafíos y Posibilidades
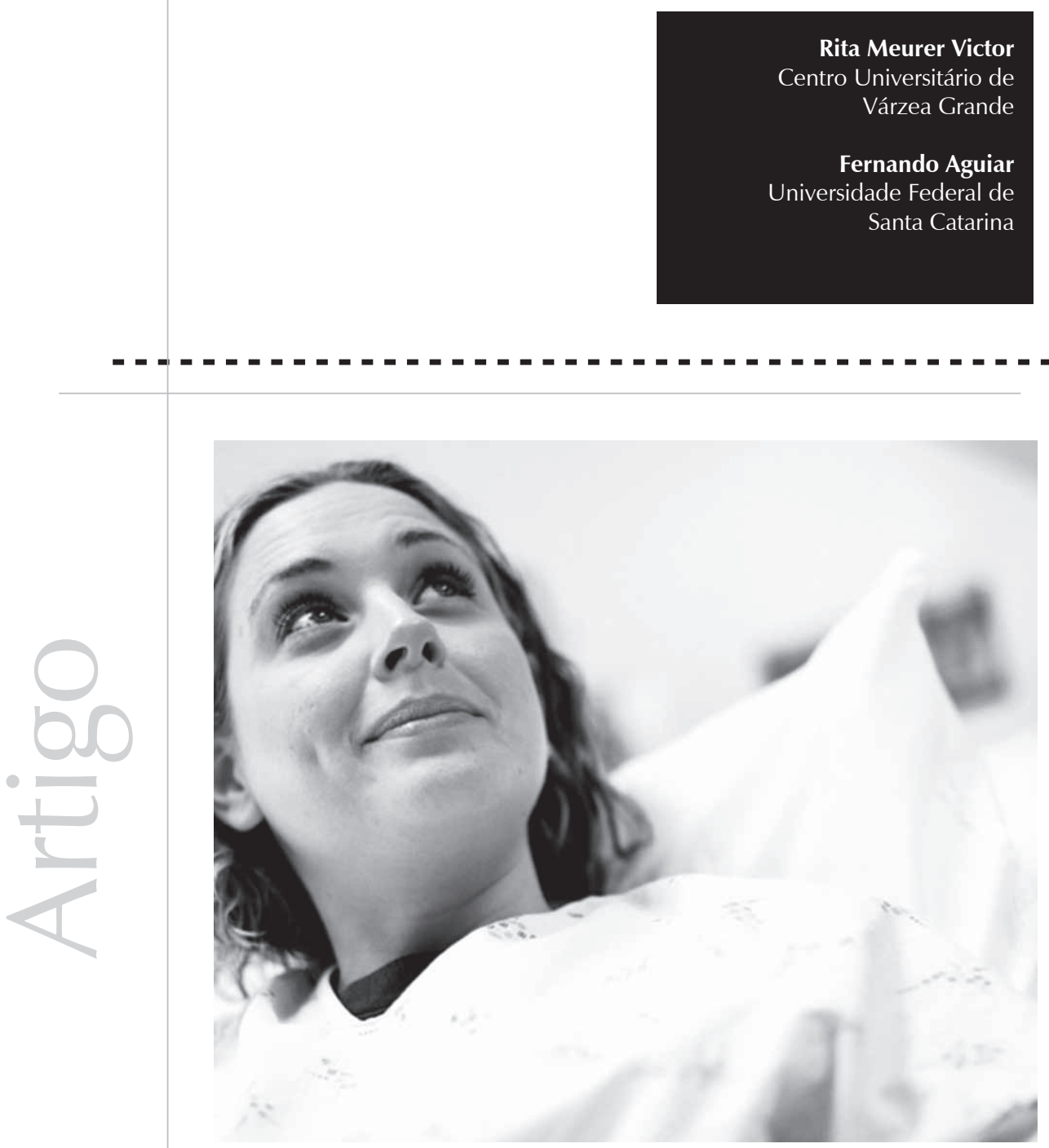
Resumo: A partir da reforma sanitária, na década de 1970, e da criação do Sistema Único de Saúde - SUS, em 1988, os serviços ambulatoriais foram fortalecidos no Brasil. Constituídos por equipes interdisciplinares, a presença do psicanalista é neles cada vez mais comum. Entretanto, ainda que diversas áreas científicas se façam presentes nas equipes ambulatoriais, a hegemonia médica é indiscutível, o que muitas vezes culmina em dificuldades para a prática do psicanalista. Com isso, a viabilidade da clínica psicanalítica nos ambulatórios brasileiros é constantemente questionada e ameaçada, pois são inúmeras as divergências entre as demandas institucionais e o trabalho analítico. Diante desse contexto, este artigo tem como objetivo central a investigação dos impasses que ocorrem entre a psicanálise e as equipes dos ambulatórios médicos. Trata-se de um trabalho teórico, cujas fontes foram as produções bibliográficas a respeito do tema. Como conclusão, destaca-se que, apesar dos entraves e constantes desafios aos quais é submetida, a prática psicanalítica é plenamente viável e efetiva nos ambulatórios públicos brasileiros.

Palavras-chave: Psicanálise. Psicologia clínica na saúde. Medicina. Saúde pública.

Abstract: Since the health care reform, in the 70's, and the creation of the Unified Health System, in 1988, the outpatient services have been strengthened in Brazil. Consisting of interdisciplinary teams, the presence of the psychoanalyst in these services has been increasingly more common. However, even though various scientific areas are present in the outpatient teams, the medical hegemony is unquestionable, what many times leads to difficulties in the practice of the psychoanalyst. Therefore, the viability of the psychoanalytic clinic in Brazilian outpatient services is constantly questioned and threatened as far as uncountable are the differences between the institutional demands and the analytical work. In this framework, this article has as main objective the investigation of the impasses that occur between psychoanalysis and the medical outpatient teams. This is a theoretical work whose sources were the bibliographic production concerning the subject. As conclusion, it is emphasized that, despite the conflicts and the constant challenges that it is submitted to, the psychoanalytic practice is fully viable and effective in Brazilian public outpatient clinics. Keywords: Psychoanalysis. Clinical health psychology. Medicine. Public health.

Resumen: A partir de la reforma sanitaria, en la década de 1970, y de la creación del Sistema Único de Salud - SUS, en 1988, los servicios de ambulatorio fueron fortalecidos en el Brasil. Constituidos por equipos interdisciplinares, la presencia del psicoanalista es en ellos cada vez más común. Sin embargo, aunque diversas áreas científicas se hagan presentes en los equipos de ambulatorio, la hegemonía médica es indiscutible, lo que muchas veces culmina en dificultades para la práctica del psicoanalista. Con eso, la viabilidad de la clínica psicoanalítica en los ambulatorios brasileños es constantemente cuestionada y amenazada, pues son innúmeras las divergencias entre las demandas institucionales y el trabajo analítico. Delante de ese contexto, este artículo tiene como objetivo central la investigación de los puntos muertos que ocurren entre el psicoanálisis y los equipos de los ambulatorios médicos. Se trata de un trabajo teórico, cuyas fuentes fueron las producciones bibliográficas a respecto del tema. Como conclusión, se destaca que, a pesar de los problemas y constantes desafíos a los cuales es sometida, la práctica psicoanalítica es plenamente viable y efectiva nos ambulatorios públicos brasileiros.

Palabras clave: Psicoanálisis. Psicologia clinica de la salud. Medicina. Salud pública.

A atuação do psicanalista vem se tornando hoje tão relevante na saúde pública quanto na clínica privada, e se distribui em todos os níveis de assistência do Sistema Único de Saúde (SUS): na primária, junto aos postos de saúde e no Programa de Saúde da Família, na secundária, através das policlínicas e ambulatórios, e na terciária, nos complexos hospitalares. Mas, como a função de psicanalista não é regulamentada pelo Estado, a presença desse profissional nos serviços públicos de deve às conquistas da Psicologia como profissão.

Até a década de 70, o campo de atuação da Psicologia era composto por duas dimensões principais: a primeira, constituída pela clínica particular, era exercida de forma autônoma; já a segunda, desenvolvida conforme o modelo de atenção predominante da época, o de internação e medicação (Dimenstein, 1998), compreendia as atividades desempenhadas em hospitais e ambulatórios de saúde mental e subordinadas aos paradigmas da psiquiatria.

Um dos fatores que contribuiu para o surgimento da Psicologia da saúde foi a crescente insatisfação com a medicina então praticada. Sua motivação encontrava-se nas dificuldades em englobar uma nova epidemiologia que incorporasse fatores psicológicos, sociais e econômicos, e deveu- 
se também ao desenvolvimento de terapias psicológicas focadas em queixas físicas, demonstrando que o dualismo cartesiano mente-corpo (base da Medicina) deveria ser reexaminado (Marteu \& Johnson 1989, citado por Dimenstein, 1998).

No Brasil, a participação do profissional psicólogo na área da saúde iniciou-se ainda na década de 70, mediante uma ação mais ampla nos cuidados primários. Desde então, esses cuidados, anteriormente restritos à ação médica, tiveram a participação da Psicologia e do Serviço Social. Essa inserção originou-se de um movimento mais geral no Brasil, a reforma sanitária, e concretizou-se no movimento dos psicólogos através de associações de classe, que reivindicaram espaço nos centros e postos de saúde. Tais reivindicações decorreram do entendimento segundo o qual o atendimento clínico psicológico não seria apenas de caráter curativo, mas abrangeria também ações preventivas e de promoção de saúde (Kahhale, 2003).

Essa inserção do psicólogo nos serviços públicos de saúde ocorreu paralelamente a um movimento dentro da própria Psicologia, com o desenvolvimento da Psicologia social comunitária - introduzida assim em territórios antes pertencentes a outras disciplinas -, sendo este um período de importantes avanços. Novas concepções passaram a integrar a Psicologia clínica, como o caráter global da saúde e a necessidade de trabalhos interdisciplinares no cuidado das populações e da comunidade. Com o advento da reforma sanitária, a saúde é entendida como um direito a ser conquistado, e que envolvia prevenção e promoção, além da cura e da reabilitação (Kahhale, 2003). Tal visão ampliada propicia um ambiente favorável à entrada do psicólogo - e, pela mesma via, do psicanalista.

Contudo, se o psicanalista se faz cada vez mais presente na saúde pública, e se sua inserção ocorre, sobretudo, através do profissionalpsicólogo, suas dificuldades e desafios são distintos e particulares, e merecem um exame à parte. Este artigo pretende justamente discutir a atuação do psicanalista nesse contexto que, tradicionalmente, não era o seu em nosso país.

\section{Ainda um pouco de história da Psicologia...}

O processo de constituição da Psicologia da saúde pode ser mais bem apreendido quando equacionado à composição da Medicina social como campo de saber, cujo objetivo inicial foi a modernização do ensino médico e a estimulação da consciência social desses profissionais. O processo de construção desse campo do saber levou cerca de vinte anos, entre a década de 50 e os primeiros anos da década de 70 .

O período em questão caracteriza-se por três etapas: a primeira, que se distingue pelo despertar do interesse no processo saúde/ doença, possui uma grande diversidade metodológica, pois ainda está em vias de descobrir novos campos de atuação; a segunda, marcada pela definição ideológica dos integrantes do grupo, pode ser definida pela crítica ao positivismo e pela aplicação do materialismo histórico ao estudo do processo saúde/doença; a terceira etapa, enfim, constitui um aprofundamento da anterior, porém mais voltada para a pesquisa. Esse movimento, embora fundamental para a reforma sanitária brasileira, não foi suficiente para provocar mudanças relevantes na postura e na prática dos profissionais médicos (Dimenstein, 1998). Refletir sobre essa atuação de forma mais profunda tem sido o objetivo desse campo de saber.

Um dos desafios da Psicologia é englobar o aspecto político em sua atuação na saúde pública. Com uma tradição atrelada a perspectivas ora objetivo-positivistas, ora interno-subjetivas, a Psicologia tende a conceber o indivíduo abstraído de seu contexto, o que culmina em práticas despolitizadas. Faz-se necessário ressaltar que nem todas as correntes psicológicas partilham dessa postura a-histórica. Práticas mais conectadas aos aspectos políticos e sociais têm revelado resultados satisfatórios nos diversos níveis de atenção da saúde pública, embora a predominância da Medicina, com sua matriz positivista, tenda a estabelecer um ambiente mais acolhedor às correntes psicológicas que melhor respondam à sua demanda, ou seja, a assessoria focal: 
O afastamento entre a psicanálise e a psiquiatria se deu no momento em que a invenção de Freud deixou de ser entendida como uma técnica terapêutica da psiquiatria para constituir um novo tipo de abordagem da doença mental, com características distintas - fato influenciado também pela criação, no País, de instituições psicanalíticas (Rocha, 1989). trabalhando com aspectos isolados, não há risco de atrapalhar o tratamento médico (Benevides, 2005). O ano 2006 foi eleito pelos Conselhos de Psicologia como o ano da saúde, e nele ocorreu o primeiro fórum nacional sobre Psicologia e saúde pública. Nesse fórum, foi debatido, dentre outros assuntos, o desafio de ampliação da presença da Psicologia nesse campo, uma vez que esta teria como vocação a promoção do bemestar e a ampliação da qualidade de vida dos indivíduos, dos coletivos e das instituições. Diante do Plano Nacional de Humanização, a Psicologia, quando se trata da sua inserção no campo da saúde pública, precisaria operar uma série de enfrentamentos relativos à base conceitual e ao repertório de práticas que lhe são próprias.

\section{... e da psicanálise na saúde pública}

A psicanálise, por sua vez, esteve vinculada, no Brasil, à psiquiatria na primeira metade do século passado, e com seu suporte teórico privilegiou-se a relação com o louco. O afastamento entre a psicanálise e a psiquiatria se deu no momento em que a invenção de Freud deixou de ser entendida como uma técnica terapêutica da psiquiatria para constituir um novo tipo de abordagem da doença mental, com características distintas - fato influenciado também pela criação, no País, de instituições psicanalíticas (Rocha, 1989).

Na saúde pública, a entrada da psicanálise ocorreu através do profissional psicólogo, fato ainda hoje comum, pois não existe nos quadros funcionais o cargo de psicanalista. Mas a psicanálise enfrenta desafios distintos, antes de tudo porque não pretende primariamente ampliar a qualidade de vida dos indivíduos, mas propiciar uma escuta diferenciada a quem está em sofrimento. E, em face dessa discordância, tampouco objetiva repensar sua base conceitual, mas, ao contrário, fortalecê-la para intervir de maneira adequada, advertida, interessada. A presença da psicanálise no ambulatório público de certa maneira foi prevista por Freud em Linhas de Progresso na Terapia Psicanalítica (1919/1974), ao sustentar que, em algum momento, a sociedade despertaria para a necessidade de oferecer a escuta analítica a toda a população, não importando a classe social. Ele próprio cogitou de criar instituições gratuitas compostas por analistas visando aos pacientes sem condições de bancá-los na clínica privada.

Em 1920, Karl Abraham, juntamente com Max Eitingon e Ernst Simmel, inaugurou o Instituto Psicanalítico de Berlim, onde foram desenvolvidos tratamentos terapêuticos gratuitos, para os menos favorecidos e pagos, em graus variáveis, para os outros pacientes (Roudinesco \& Plon, 1998). Tal proposta terapêutica serviu de modelo para vários países, e é até hoje praticada por diversas instituições psicanalíticas.

Os ambulatórios públicos brasileiros diferem em dois aspectos fundamentais da conjectura de Freud sobre o futuro. Em primeiro lugar, as instituições são constituídas por equipes interdisciplinares e não somente por analistas. Em segundo, e mais importante, é que, marcadas pelo discurso médico, essas equipes tendem a preferir terapias psicológicas focadas no ajustamento de comportamentos e emoções do paciente, para que este responda de maneira adequada ao tratamento médico ao qual estiver submetido. Assim como no tempo de Freud, a psicanálise ainda difere radicalmente - e talvez mais do que nunca - do discurso dominante nessas instituições, marcando um ponto de resistência à concepção do paciente como passivo, alienado, a-histórico e desprovido de qualquer saber referente a si próprio.

Já no período final de sua vida e obra, no texto Explicações, aplicações e orientações, de suas novas conferências (1932/1974), Freud discutiu as resistências à psicanálise e reafirmou o método psicanalítico e os conceitos fundamentais. Um dos alvos dos questionamentos foi, por exemplo, a longa duração do tratamento, que ele sempre justificou com o fato de que as modificações psíquicas só ocorrem muito lentamente.

Uma boa parte dos psicanalistas, talvez até inspirados no cuidado de Freud com a sua invenção, não costuma fazer concessões a respeito da aplicação clínica da psicanálise, 
aferrando-se à teoria e tornando-a rígida em relação à prática clínica. Algumas características do trabalho do analista no serviço público - por exemplo, o fato de ele ser um servidor público, que não recebe pagamento do paciente, além de este se apresentar como possuidor do direito ao tratamento - bastam para que muitos psicanalistas considerem inviável a sua prática nessas condições. Ocorrem aí dois golpes narcísicos de uma só vez: a perda do controle sobre o dinheiro e a relação do poder de decisão sobre assumir ou não determinado paciente (Figueiredo, 2001).

Não é raro acontecer de o psicanalista atender algum paciente cuja demanda não seja de um trabalho analítico. Se o fato ocorresse no consultório privado, dispensá-lo-ia sem maiores dificuldades, mas, na instituição, esse ato requer certos cuidados, pois, munido de seus direitos, o paciente pode alegar (lembrando sempre a inexistência da função de psicanalista nos serviços públicos brasileiros) que lhe foi negado o atendimento pelo psicólogo. Essa reclamação, chegando à gerência, pode culminar na determinação de que o psicanalista atenda novamente o paciente - o que seria um complicador a mais. Outra possibilidade é a de o fato gerar uma denúncia na ouvidoria do órgão, o que suscita um processo administrativo no qual o psicanalista terá que fazer a sua defesa. Por isso, muitas vezes, ele tem como saída prosseguir com os atendimentos por algumas sessões, para só depois dar alta. Esse procedimento, aliás, que exige alguma perícia do profissional, foi mesmo previsto por Freud (1913/1974) e está enquadrado no tópico desenvolvido sob o nome de Entrevistas preliminares, em seu texto Sobre o início do tratamento.

Outra particularidade do trabalho institucional é a convivência com a equipe. Nas equipes interdisciplinares, cada profissional se responsabiliza pelo que sabe e, no seu limite, é completado pelo saber de outro profissional. Considera-se que exista um bom funcionamento da equipe, portano, quando vigora a lógica do conjunto, tudo pelo bom resultado do trabalho. No caso de acontecer fracassos com os casos, ocorrem efeitos imaginários como a atribuição da falha ao pouco saber de alguém da equipe ou, o mais comum, porque algum profissional não fez o que deveria ter feito (Lambert, 2003). Não é difícil concluir qual membro da equipe recebe sucessivamente críticas por não ter feito o que lhe foi atribuído: o psicanalista. Porque a psicanálise parte de outros princípios teórico-epistemológicos e de outra ética, que supõem a inexistência de um objeto adequado e a impossibilidade da totalidade e da completude harmônica, o psicanalista não se encaixa muito bem nesse funcionamento de equipe, o que produz dificuldades de trabalho. Em uma palavra, não raro a equipe tenta projetar seus fracassos no psicanalista.

Um bom exemplo é o caso dos tratamentos clínicos de obesidade mórbida. Na maioria dos casos, o paciente busca o serviço por conta própria, é atendido inicialmente pelo médico endocrinologista, que, por sua vez, o encaminha aos demais profissionais (nutricionista, enfermeiro, assistente social, educador físico e psicólogo). Em uma grande parcela dos casos, mesmo munidos de remédios, dietas e programas de condicionamento físico, o paciente passa longe dos objetivos traçados no plano de tratamento. A equipe de profissionais, certa de fazer um bom trabalho, crê que o paciente continua obeso porque houve uma falha no trabalho do analista, que não trabalhou de maneira efetiva a ansiedade ou a depressão do paciente. Como legítimos representantes da ciência, esses profissionais ignoram o discurso do analista, e não aceitam outra forma de tratar o paciente que não seja normativa e pedagógica. Com isso, o psicanalista se torna o problemático da equipe, aquele que tem dificuldades em cooperar.

A equipe demanda um psicoterapeuta, e não um psicanalista, porque a psicoterapia aposta na capacidade do sujeito em se instrumentalizar com os conselhos do terapeuta para vencer suas dificuldades e angústias, em se fortalecer e responder de maneira adequada ao tratamento de sua patologia. A psicanálise, por nada disso prometer, é tida como menos competente que a psicoterapia (Sauret, 2006). Tal contraste se pauta na ética da psicanálise, 
que serve de guia para o analista operar o seu discurso em um terreno epistemologicamente distinto, como o ambulatório. A ética da psicanálise afirma a diferença, a singularidade, em detrimento da normatização. Fazer esse contraponto na instituição de saúde é, muitas vezes, arcar com o ônus da resistência da equipe, pois ressalta o estrangeirismo do discurso analítico. Porém, os inúmeros pacientes que entram em trabalho analítico e também os profissionais que vão, pouco a pouco, verificando os consistentes efeitos proporcionados pela psicanálise aliviam, de certa maneira, o mal-estar que o psicanalista suporta para efetivar o seu trabalho.

A duração do tratamento é igualmente um fator delicado para o psicanalista inserido no campo institucional. As normas de tempo são variáveis, seja quanto ao tempo médio de sessões, seja quanto à permanência do paciente em tratamento com os demais profissionais. Poucas vezes são essas normas que determinam diretamente a decisão de concluir o tratamento. Mesmo existindo uma norma, na maioria dos casos, há sempre certa margem de flexibilidade e de manobra individual que permite ao psicanalista decidir a conclusão de acordo com os seus próprios critérios e com as características de cada caso.

Com isso, pode-se dizer que há certa tensão entre a liberdade do profissional e a norma institucional. Apesar de estabelecer diretrizes para os términos dos tratamentos, a instituição conhece minimamente as diferenças das abordagens que o psicólogo pode seguir e sabe que o profissional possui certa liberdade para encerrar seu trabalho de acordo com a própria abordagem. Quando as normas de tempo de permanência no tratamento são mais flexíveis, aumenta-se a responsabilidade do psicanalista, pois este sabe que nenhum paciente na rede pública de saúde fará uma análise até o fim (Rubistein, 2005).

Não ter controle sobre o dinheiro, atender pacientes sem demanda de trabalho analítico, enfrentar dificuldades com a equipe interdisciplinar e ter que decidir sobre a duração do tratamento são apenas alguns dos desafios da psicanálise na instituição. Por esse viés, ela é uma prática distinta da prática clínica do consultório particular, pois está inserida em um campo atravessado pelo discurso científico dominante.

A psicanálise não está no ambulatório para negar os avançados tratamentos das mais diversas patologias, mas para ouvir os sujeitos que portam tais patologias. Por isso, mesmo com inúmeras dificuldades, há possibilidades efetivas de trabalho para o psicanalista. Dito de outra maneira, a psicanálise não se opõe aos avanços da ciência, até porque seria impossível negligenciar tais avanços. Entretanto, pode-se afirmar que, no seio da produção científica, os trabalhos se dividem entre os que incluem a interação com o Outro da linguagem nas determinações do sofrimento psíquico e os que negam ou tendem a negar esse ponto de vista. Constata-se que a contemporaneidade parece reafirmar a dicotomia cartesiana; nesse contexto, a psicanálise propõe o restabelecimento da implicação subjetiva do sujeito (Veras \& Besset, 2007).

\section{Precisões necessárias}

Distintamente das inúmeras abordagens psicoterápicas, o trabalho analítico não tem como foco os efeitos terapêuticos. Estes são inegáveis e geralmente não tardam a aparecer, mas de maneira alguma é (primariamente, como já afirmado) o objetivo do tratamento analítico, isso porque a psicanálise não visa a normalizar o sujeito ou a adequá-lo à realidade, por entender que essa seria uma tarefa impossível.

A psicoterapia explora e exalta a dimensão imperativa do significante; já a psicanálise visa a reduzi-la. Em outras palavras, a psicoterapia reproduz o discurso do mestre, o discurso em que há um representante do saber - e os médicos e muitos outros profissionais tendem a ocupar esse lugar, definindo o melhor caminho para o paciente, por sua vez colocado no lugar de desconhecimento (Coutinho Jorge, 2006). O analista se recusa a fazer esse jogo. O S1 (significante-mestre) que o analista quer sustentar é o do sintoma do sujeito, e não o significante-mestre da civilização. Com isso, ele pode formular as condições de uma psicanálise aplicada à terapêutica - uma possibilidade viável de adequação à demanda 
institucional - que não se relacione em nada com a psicoterapia (Laurent citado por Stevens, 2007). Uma instituição é orientada por um significante-mestre da civilização: no caso do ambulatório, o saber médico; logo, uma vez dentro desse conjunto, o psicanalista não deve se impor, se opor ou se colocar a serviço do mestre, mas sim, furar os S1 da instituição (Stevens, 2007).

Realizar esse trabalho na instituição não é simples, pois o psicanalista se vê confrontado com pacientes cuja demanda já está modulada pelo efeito de um discurso medicalizado, ou seja, uma demanda que se endereça ao saber médico (Menard, 2007): o sujeito dirige-se ao ambulatório crendo que será atendido por vários doutores, por isso é comum sentirse confuso quando descobre que o doutor psicólogo não medica, só conversa.

De início, o analista não está situado como sujeito suposto saber - essa função é dividida entre os membros da equipe de atendimento. Com o decorrer do tratamento, o paciente costuma eleger um profissional como sujeito suposto saber, que pode não ser o analista. Se a demanda de sentido que o paciente apresenta for recebida de maneira satisfatória por outro profissional, o trabalho do analista pode ser inviabilizado, o que de maneira nenhuma deve ser entendido como perda para o paciente, pois a escuta analítica só pode promover efeitos para quem a deseja: parafraseando o Direito, a psicanálise existe para quem a busca, e nisso se alicerça sua diferença. Se ela quisesse submeter todos os pacientes ao processo analítico, crendo que isso seria o melhor para eles, estaria normatizando - exatamente como o discurso médico. Justamente por não conceber o paciente como passivo, a psicanálise entende que seu discurso não vai ao encontro da demanda de todos os sujeitos, cabendo a estes julgar se a desejam ou não.

Com tudo isso, o psicanalista é constantemente desafiado a se adaptar e a se adequar. Nos ambulatórios ainda dominados pelo discurso médico, o analista se faz presente para nada mais do que operar o discurso analítico e oferecer aos sujeitos a possibilidade de falar de seu sofrimento. No ambulatório público, nenhum sujeito fará análise no sentido estrito, mas pode ter uma experiência analítica de curta duração, de acordo com a orientação lacaniana referente às entrevistas preliminares.

D’Angelo (2005) esclarece que uma experiência psicanalítica de curta duração não se assemelha de maneira alguma às chamadas psicoterapias breves ou focais:

... A diferença entre uma psicoterapia breve, que promove a modificação ou eventualmente o desaparecimento do sintoma, do que é um efeito terapêutico rápido, que reduz o gozo implicado no sintoma do sujeito e que relança um novo ciclo em direção da cura. (p. 37)

Com uma psicanálise aplicada à terapêutica, pode-se responder à demanda social sem perder de vista os princípios que dirigem o ato analítico. A transferência continua sendo a condição de possibilidade do trabalho, e em nenhum momento o analista passa por psicoterapeuta, porque não busca de forma alguma normalizar, no sentido do ideal, elementos que para a psicanálise são intrinsecamente irrazoáveis, como o desejo e o gozo.

A aplicação da psicanálise à terapêutica, como tratamento, em determinada hora, em determinada problemática, em determinado lugar, e a demonstração de sua oportunidade, conveniência e possibilidade de ação para além das condições imanentes à prática de consultório constituem, em nossos dias, o desafio da psicanálise de orientação lacaniana (Santana Nel, 2007, p. 103)

Essa conduta tem como objetivo fazer da psicanálise uma prática viável e relevante nos tempos atuais, pois contrapõe o universal das normas ao singular de cada um, visando a alcançar a subjetividade dos sujeitos de sua época. A proposta de tratamento de curta duração, portanto, não é uma saída desqualificada para a psicanálise, mas a prova de que o discurso analítico pode se fazer presente e efetivo em circunstâncias diversas (Gurgel, 2003). É necessário jogo de cintura para que haja um bom convívio, em 
vez de se tentar converter os profissionais à psicanálise. Ao analista, não compete transformar a concepção de homem do saber médico, pois ele não está no ambulatório para impor, nem tampouco para acatar. Ele se faz presente para contribuir, para ofertar uma visão diferenciada. A proposta da experiência de curta duração é o passo que a psicanálise dá em direção às necessidades atuais dos serviços públicos. É o reconhecimento de que a adequação é possível e de que o discurso psicanalítico é viável nos tempos atuais.

É a aposta na causa freudiana de que o desejo - índice da presentificação do sujeito - é a Fênix que sempre renasce - por maiores que sejam as dificuldades que encontramos e cujas etiologias vão desde a falta de recursos até a cientificização dos discursos, passando pelas dificuldades do trabalho em equipe, pela resistência ao tratamento e pelos interesses econômicos, que nem sempre levam em conta o sujeito e a reação terapêutica negativa, para citar somente algumas (Figueiredo \& Alberti, 2006, p. 9). Sob vários aspectos - da origem profissional de seu fundador a questões de ordem político-institucionais - a psicanálise mantém relações com a Medicina desde sua criação. Mas tal proximidade - basicamente, o fato de que ambas investigam e buscam tratar as (ditas) doenças psíquicas - serviu muito mais a Freud para afirmar a radical diferença entre ambas. Mais de uma vez em sua obra referiu-se à formação, distinta, de médicos e psicanalistas, e em A questão da análise leiga, de 1926/1974, externou sua preocupação com a possibilidade de a psicanálise ser reduzida a uma modalidade terapêutica da Medicina. Como tal, defendeu a formação de psicanalistas leigos, quer dizer, não médicos ou não originários do campo médico.

Freud destacou que a formação do médico é oposta ao que necessitaria um psicanalista. A atenção voltada para fatos objetivamente verificáveis, a crença de que o êxito do tratamento depende de tais observações e, principalmente, a busca de seu saber, no qual a subjetividade se encontra, por tradição, denegada, faz da Medicina um campo radicalmente distinto da psicanálise. $\mathrm{Na}$ conferência I, de suas Conferências
Introdutórias sobre Psicanálise (1917/1974), Freud explica que, em sua formação, o médico se acostuma a ver coisas, ou seja, reações químicas, preparações anatômicas, etc. Já na psicanálise, nada acontece além de um intercâmbio de palavras entre o paciente e o psicanalista.

Tal preocupação de Freud - a redução da psicanálise a uma modalidade terapêutica da Medicina - não se concretizou, embora, em contrapartida, a psiquiatria, ramo da Medicina, tenha sido grandemente influenciada pelo saber psicanalítico ao menos até a década de 50, período de criação dos primeiros psicofármacos. Por outro lado, em que pesem as distorções, adaptações e ataques de que foi vítima, a psicanálise se transformou em uma das grandes correntes teóricas do século XX. Em particular, a Pedagogia e a Psicologia foram tradicionalmente marcadas pela criação freudiana, mas essa influência, de impressionante magnitude, atingiu inúmeros outros campos de saber. Conceitos como complexo de Édipo, inconsciente, fase oral, fixação, trauma e tantos outros foram absorvidos pela cultura popular no mundo ocidental, resultando, como óbvia consequência, em reducionismos diversos e em confusão.

A partir da segunda metade do século $X X$, gradativamente a psicanálise foi sendo desacreditada pela Medicina. O desenvolvimento das neurociências contribuiu para a reconstrução da Medicina mental, e assim a psiquiatria foi cientificizada (Birman, 2007). Com isso, as terapias cognitivas tiveram uma grande aceitação, pois, dentre as modalidades terapêuticas existentes, são as que melhor se adequam à nova medicina. Paralelamente, as transformações econômicas e sociais se refletiram na subjetividade dos indivíduos ocidentais. Mezan (2000) explica que a modernização do século XX culminou em importantes mudanças nas mentalidades e comportamentos, e o indivíduo ocidental deixou de viver sob o grande controle exercido pela repressão social. A sociedade tornou-se mais permissiva nos aspectos referentes à vida sexual e privada, mas passou a impor o alto consumo como sinônimo de sucesso. 
Atualmente, e mais do que nunca, o ser é substituído pelo ter. O indivíduo é todo o tempo atingido pelas novas tecnologias, novas informações e novos objetos de desejo. Os ideais são referenciados no consumo: ter um corpo perfeito, adquirir os objetos tecnológicos mais avançados, usufruir dos tratamentos mais recentes... Obviamente, se a lógica ocidental-contemporânea gira em torno do consumo, o bem-estar também se referenciará na ordem do ter. Ora, há uma relação entre esse atual estado de coisas e certa caracterização da psicanálise como uma teoria e uma forma de tratamento ultrapassadas.

\section{Considerações finais}

O alto consumo tem uma relação fundamental com o tempo. Tudo é perecível; o que agora é bom, amanhã não serve mais. Por se adequar aos moldes da contemporaneidade, e contribuir com eles, a concepção hegemônica na Medicina condiciona cada vez mais a eficiência à rapidez. Não basta restituir a saúde e o bem-estar, é fundamental que isso ocorra rapidamente. Não há tempo para se envolver com o seu mal-estar, buscar suas causas, construir novas maneiras de lidar com ele, responsabilizar-se. O objetivo não é procurar alternativas para a angústia inerente a todo ser humano, mas sim, comprar o seu antídoto.

Essa lógica é claramente percebida nos ambulatórios. A necessidade instituída de que o paciente deve se adaptar ao tratamento submetido e suprimir os seus sintomas está em consonância com esse molde de viver. A contemporaneidade almeja a robotização, tanto no seu aspecto de comportamentos e reações desejáveis quanto no aspecto não humano, ou seja, sem conflitos e sem sofrimento.

A psicanálise segue na contramão desse processo ao defender a impossibilidade de erradicação do sofrimento, e aposta na singularidade do sujeito em detrimento da robotização dos indivíduos. Mezan (2005) refere-se a uma infantilização crescente das pessoas, a uma tendência a evitar a responsabilidade individual - tendência que coloca em risco a autonomia, valor herdado do Iluminismo e que a psicanálise considera imprescindível. Em consequência, a psicanálise é rotulada de inapropriada aos tempos atuais, resistente às descobertas científicas, incapaz de se adequar.

Uma vez inserido no ambulatório, ou em qualquer outro campo institucional, o psicanalista tem a sua prática atingida por tais valores contemporâneos. Mas não foi sempre assim? A psicanálise, desde os seus primórdios, não enfrentou resistências, desconfianças e críticas, e sempre resistiu justamente porque seu discurso é efetivo e transformador? Isso pode ser amplamente verificado no ambulatório. Apesar de a clientela dessas instituições possuir baixo nível cultural, sérios problemas econômicos e ser atravessada pelos ideais contemporâneos de medicalização do sofrimento e por terapias breves para supressão dos sintomas, a presença do discurso analítico cria a demanda de uma escuta analítica em muitos pacientes. Eé nesse fato que a psicanálise se apoia para afirmar a sua importância nos tempos atuais.

Indo mais além, a inconsistência dos efeitos terapêuticos promovidos pelas medicações psicotrópicas e o alto índice de incidência das novas formas de adoecer (depressões, síndromes do pânico, distúrbios alimentares) mostram que os ideais contemporâneos não sustentam o discurso que buscam promover. É nessa situação que a psicanálise se revigora, tornando-se imprescindível como ponto de limite a esse discurso.

A psicanálise não vai salvar a sociedade, ou a instituição de saúde, e nem pretende tal coisa. Mas também não será devorada por esse discurso hegemônico, porque ela se torna necessária à medida que esse discurso tenta mais e mais capturar o sujeito para subordinálo aos seus ideais. 


\section{Rita Meurer Victor}

Mestre em Psicologia pela UFSC, Santa Catarina - SC - Brasil.

E-mail.mv_rita@hotmail.com

\section{Fernando Aguiar}

Doutor em Filosofia pela UCL (Bélgica), professor associado II do Departamento de Psicologia e do Programa de Pós-Graduação em Psicologia da UFSC, Santa Catarina - SC - Brasil.

E-mail. aguiarfe@hotmail.com

\section{Endereço para envio de correspondência:}

Avenida São Sebastião, 1269, apto 306, bairro Goiabeiras, Cuiabá - MT - Brasil CEP 78032-100.

Recebido 26/7/2009, 1a Reformulação 7/6/2010, 2a Reformulação 22/8/2010, Aprovado 8/9/2010.

\section{Referências}

Benevides, R. (2005). A psicologia e o Sistema Único de Saúde: quais interfaces? Psicologia e Sociedade, 17(2), 21-25. Recuperado em 31 março de 2008, de http://www.scielo. br/scielo/.

Birman, J. (2001). Despossessão, saber e loucura: sobre as relaçôes entre psicanálise e psiquiatria hoje. In A. Quinet (Org.), Psicanálise e psiquiatria. Controvérsias e convergências (pp. 21-29). Rio de Janeiro: Rios Ambiciosos.

Birman, J. (2007). Mal-estar na atualidade. A psicanálise e as novas formas de subjetivação (6a ed.). Rio de Janeiro: Civilização Brasileira.

Coutinho Jorge, M. A. (2006). "A psicoterapia conduz ao pior" - apontamentos sobre a querela psicanálise/psicoterapia. In A. C. Figueiredo, \& S. Alberti (Orgs.), Psicanálise e saúde mental: uma aposta (pp. 127-139). Rio de Janeiro: Companhia de Freud.

D’Angelo, L. (2005). Terapias breves versus efectos terapêuticos rápidos. In J. A. Miller, L. D’Angelo, A. Fuentes, C. Garrido, A. Goya, F. Rueda, \& A. Vicens. Conversaciones clínicas con Jacques Alain Miller (pp. 34-41). Buenos Aires: Pardós.

Dimenstein, M. D. B. (2006). A prática dos psicólogos no Sistema Único de Saúde/SUS. In 1 Fórum Nacional de Psicologia e Saúde Pública: contribuições técnicas e políticas para avançar o SUS. (pp. 8-16). Brasília, DF: Conselho Federal de Psicologia.

Dimenstein, M. D. B. (1998). O psicólogo no contexto do Sistema Único de Saúde (SUS): perfil profissional e perspectivas de atuação nas Unidades Básicas de Saúde (UBSs). Tese de doutorado em Psiquiatria, Psicanálise e Saúde Mental, Universidade Federal do Rio de Janeiro, Rio de Janeiro.

Figueiredo, A. C. (2001). O que faz um psicanalista na saúde mental? In M. T. Cavalcanti, \& A.T. Venancio (Orgs.), Saúde mental: campo, saberes e discursos (pp. 73-82). Rio de Janeiro: IPUB/UFRJ.

Figueiredo, A. C., \& Alberti, S. (Orgs.). (2006). Psicanálise e saúde mental: uma aposta. Rio de Janeiro: Companhia de Freud.

Freud, S. (1974). Além do princípio de prazer. In Edição Standard Brasileira das obras psicológicas de Sigmund Freud (I. Salomão, Trad., Vol. 28, pp. 17-85). Rio de Janeiro: Imago (Trabalho original publicado em 1920).

Freud, S. (1974). A questão da análise leiga. In Edição Standard Brasileira das obras psicológicas de Sigmund Freud (J. Salomão, Trad., Vol. 20, pp. 211-283). Rio de Janeiro: Imago (Trabalho original publicado em 1926).

Freud, S. (1974). Conferências introdutórias sobre psicanálise (partes I e II). In Edição Standard Brasileira das obras psicológicas de Sigmund Freud (J. Salomão, Trad., Vol.15, pp. 27-285). Rio de Janeiro: Imago (Trabalho original publicado em 1917).

Freud, S. (1974). Conferências introdutórias sobre psicanálise (parte III). In Edição Standard Brasileira das obras psicológicas de Sigmund Freud (J. Salomão, Trad., Vol.16, pp. 289-540). Rio de Janeiro: Imago (Trabalho original publicado em 1917).

Freud, S. (1974). Linhas de progresso na terapia psicanalítica. In Edição Standard Brasileira das obras psicológicas de Sigmund Freud (J. Salomão, Trad., Vol. 17, pp. 201-211). Rio de Janeiro: Imago (Trabalho original publicado em 1919).

Gurgel, I. (2003) Psicanálise e saúde mental: de reformas \& desafios. Correio, 44(9), 29-34.

Kahhale, E. M. P. (2003). Psicologia na saúde: em busca de uma leitura crítica e de uma atuação compromissada. In A. M. B. Bock (Org.), A perspectiva sócio-histórica na formação em psicologia (pp. 161-191). Petrópolis, RJ: Vozes.

Lambert, A. (2003). Psicanálise no hospital. Opção Lacaniana, 37(9), 48-51.

Menard, A. (2007). Furar a instituição. In J. D. Matet, \& J. Miller, (Orgs.). Pertinências da psicanálise aplicada. Trabalhos da Escola da Causa Freudiana reunidos pela Associação do Campo Freudiano (pp. 98-103). Rio de Janeiro: Forense Universitária.

Mezan, R. (2000). O mal-estar na modernidade. Revista Veja, $1681(12), 68-70$.

Mezan, R. (2005). Quem está no comando? Revista Veja, 1886(4), 64-65.

Rocha, G. S. (1989). Introdução ao nascimento da psicanálise no Brasil. Rio de Janeiro: Forense Universitária.

Roudinesco, E., \& Plon, M. (1998). Dicionário de psicanálise. Rio de Janeiro: Jorge Zahar.

Rubistein. A. M. (2005). Algumas considerações sobre o término dos tratamentos com orientação psicanalítica nas instituições públicas. Revista de Psicologia Plural, 21(1), 11-36.

Santana Nel, A. (2007). Todo caso é único. A psicanálise aplicada nos permite sustentá-lo. In E. Alvarenta, E. Favret, \& C. Hortensia (Orgs.), A variedade da prática: do tipo clínico ao caso único em psicanálise (pp. 99-103). Rio de Janeiro: Contra Capa.

Sauret, M. (2006). Psicanálise, psicoterapias, ainda... In A. C. Figueiredo, \& S. Alberti (Orgs.), Psicanálise e saúde mental: uma aposta (pp. 19-43). Rio de Janeiro: Companhia de Freud.

Stevens, A. (2007). A instituição: prática do ato. In J. D. Matet, \& J. Miller, (Orgs.). Pertinências da psicanálise aplicada. Trabalhos da Escola da Causa Freudiana reunidos pela Associação do Campo Freudiano (pp. 76-85). Rio de Janeiro: Forense Universitária.

Veras, M., \& Besset, V. L. (2007). Apresentação de pacientes: a clínica lacaniana na saúde mental. Opção Lacaniana, 48(3), 130-137. 